\section{Glossary}

$K$ constant in eq $3, \mathrm{~mol} /(\mathrm{kg} \cdot \mathrm{bar})$

$L \quad$ constant in eq 3, bar $^{-1}$

$M \quad$ mass of adsorbent, $\mathrm{kg}$

$n \quad$ amount absorbed, $\mathrm{mol} / \mathrm{kg}$

$P$ pressure, bar

$q \quad$ isosteric heat of adsorption, $\mathrm{kJ} / \mathrm{mol}$

$R \quad$ gas law constant

$T$ temperature, $\mathrm{K}$

$V \quad$ gas-phase volume, $\mathrm{m}^{3}$

$x_{i} \quad$ gas-phase mole fraction

$y_{i} \quad$ adsorbent-phase mole fraction

$Z \quad$ compressibility factor

Subscripts

$i \quad$ component number

I in loading cylinder a in adsorption cell

Registry No. $\mathrm{O}_{2}, 7782-44-7 ; \mathrm{N}_{2}, 7727-37-9 ; \mathrm{Ar}, 7440-37-1$.

Literature Clited

(1) Mersmann, A.; Münstermann, U.; Schadl, J. Chem.-Ing ,-Tech, 1983 $55,446-58$.

(2) Ruthven, D. M. AIChE J. 1976, 22, 753-9.

(3) Ruthven, D. M.; Kumar, R. Ind. Eng. Chem. Fundam. 1980, 19 27-32.

(4) Peterson, D. In "Synthetic Zeolites"; American Chemical Society: Washington, DC, 1980; ACS Symp. Ser. No. 135, pp 107-21.

(5) Breck, D. W. "Zeollte Molecular Sieves"; Wiley: New York, 1974

(6) Sorial, G. A.; Granville, W. H.; Daly, W. O. Chem. Eng. Sci. 1983, 38, 1517-23.

(7) Danner, R. P.; Wenzel, L. A. AIChE J. 1968, 15, 515-20.

(8) Harwell Subroutine Library, Routine VA05A, AERE, Harwell, U.K.

Received for review January 3, 1984. Accepted August 7, 1984. H.V. carried out this work during the tenure of a N.F.W.O. Aspirant scholarship. This research was funded with grants of F.K.F.O. and V.U.B. Navorsingsraad.

\title{
Solubility of Phenylacetic Acid in Binary Solvent Mixtures
}

WIIllam E. Acree, Jr.

Department of Chemistry, Kent State University, Kent, Ohio 44242

Solubilities are reported for phenylacetic acld at $25.0^{\circ} \mathrm{C}$ In blnary mixtures of carbon tetrachloride with cyclohexane, $n$-heptane, $n$-octane, or lsooctane and mixtures of cyclohexane with $n$-heptane or lsooctane. The results are compared to the predictions of equations developed previously for solublltty in systems of purely nonspeciflc Interactions, whth phenylacetlc acid considered as elther monomeric or dimeric molecules in solution. The dimer model provided the more accurate predictions and described the 15-fold range of solubillties in the carbon tetrachloride + isooctane system to within a maximum deviation of $15 \%$.

\section{Introduction}

This work continues a systematic search $(1-8)$ for mixing models and equations which will provide reasonable predictions for the thermochemical properties of a solute in binary solvent mixtures. In an earlier paper, Acree and Bertrand (3) reported benzoic acid and $m$-toluic acid solubilities in solvent mixtures containing carbon tetrachloride. The experimental data were interpreted with solution models based on a monomeric treatment

$$
\begin{aligned}
& R T \ln \left(a_{3, \text { mon }}^{\text {solld }} / X_{3, \text { mon }}^{\text {sat }}\right)=\left(1-\phi_{3, \text { mon }}^{\text {sat }}\right)^{2}\left[\phi_{1}{ }^{\circ}\left(\Delta \bar{G}_{3, \text { mon }}^{\text {ox }}\right)^{*} x_{1}{ }^{\circ}=1+\right. \\
& \left.\phi_{2}{ }^{\circ}\left(\Delta \bar{G}_{3, \text { mon }}^{\text {ex }}\right)^{*} x_{2}{ }^{\circ}=1-\bar{V}_{3, \text { mon }}\left(X_{1}{ }^{\circ} \bar{V}_{1}+X_{2}{ }^{\circ} \bar{V}_{2}\right)^{-1}\left(\Delta \bar{G}_{12}^{\text {ex }}\right)\right] \text { (1) } \\
& R T\left[\ln \left(a_{3, \text { mon }}^{\text {solld }} / \phi_{3, \text { mon }}^{\text {sal }}\right)-\left(1-\phi_{3, \text { mon }}^{\text {sat }}\right)\left(1-\bar{V}_{3, \text { mon }} /\left(X_{1}{ }^{\circ} \bar{V}_{1}+\right.\right.\right. \\
& \left.\left.\left.x_{2}{ }^{\circ} \bar{V}_{2}\right)\right)\right]=\left(1-\phi_{3, \text { mon }}^{\text {sat }}\right)^{2}\left[\phi_{1}{ }^{\circ}\left(\Delta \bar{G}_{3, \text { mon }}^{\text {m }}\right)^{*} x_{1}{ }^{\circ=1}=1+\right. \\
& \left.\phi_{2}{ }^{\circ}\left(\Delta \bar{G}_{3, \text { man }}^{\text {h }}\right)^{*} x_{2}{ }^{\circ}=1-\bar{V}_{3, \text { mon }}\left(X_{1}{ }^{\circ} \bar{V}_{1}+x_{2}{ }^{\circ} \bar{V}_{2}\right)^{-1}\left(\Delta \bar{G}_{12}^{h}\right)\right]
\end{aligned}
$$

and a dimeric treatment

$$
\begin{aligned}
& R T \ln \left(a_{3, \mathrm{dlm}}^{\text {sold }} / X_{3, \mathrm{dim}}^{\text {sat }}\right)=\left(1-\phi_{3, \mathrm{dim}}^{\text {sat }}\right)^{2}\left[\phi_{1}{ }^{\circ}\left(\Delta \bar{G}_{3, \mathrm{dim}}^{\mathrm{ax}}\right)^{*} x_{1_{1}{ }^{\circ}=1}+\right. \\
& \left.\phi_{2}{ }^{\circ}\left(\Delta \bar{G}_{3, \mathrm{dim}}^{\mathrm{ox}}\right)^{*} x_{2}{ }^{\circ}=1-\bar{V}_{3, \mathrm{dlm}}\left(X_{1}{ }^{\circ} \bar{V}_{1}+X_{2}{ }^{\circ} \bar{V}_{2}\right)^{-1}\left(\Delta \bar{G}_{12}^{\mathrm{ox}}\right)\right] \\
& R T\left[\ln \left(a_{3, \mathrm{dim}}^{\text {solid }} / \phi_{3, \mathrm{dim}}^{\text {sat }}\right)-\left(1-\phi_{3, \mathrm{dim}}^{\mathrm{sat}}\right)\left(1-\bar{V}_{3, \mathrm{dm}} /\left(X_{1}{ }^{\circ} \bar{V}_{1}+\right.\right.\right. \\
& \left.\left.\left.x_{2}{ }^{\circ} \bar{V}_{2}\right)\right)\right]=\left(1-\phi_{3, \mathrm{dim}}^{\text {sat }}\right)^{2}\left[\phi_{1}{ }^{\circ}\left(\Delta \bar{G}_{3, \mathrm{dim}}^{\mathrm{h}}\right)^{*} x_{1}{ }^{\circ}=1+\right. \\
& \left.\phi_{2}{ }^{\circ}\left(\Delta \bar{G}_{3, \mathrm{dim}}^{\mathrm{n}}\right)^{*} x_{2}{ }^{\circ}=1-\bar{V}_{3, \mathrm{dim}}\left(X_{1}{ }^{\circ} \bar{V}_{1}+X_{2}{ }^{\circ} \bar{V}_{2}\right)^{-1}\left(\Delta \bar{G}_{12}^{\mathrm{h}}\right)\right]
\end{aligned}
$$

of the carboxylic acid. Deviations between observed and predicted values were on the order of $6-10 \%$ for eq 1 (and eq 2) and $2-4 \%$ for eq 3 (and eq 4 ).

While this eariler study did suggest that a dimeric treatment is more applicable for describing the properties of benzoic acid and $m$-toluic acid, the model should be tested by using several carboxylic acid solutes. For this reason, I have measured the solubility of phenylacetic acid in several binary solvent systems containing carbon tetrachloride with cyclohexane, $n$-heptane, $n$-octane, and isooctane and mixtures of cyclohexane with $n$-heptane and isooctane. These systems will provide a more demanding test for eq 3 and 4 as phenylacetic acid is 13 times more soluble (on a mole fraction basis) in carbon tetrachloride than in the $n$-alkane solvents.

\section{Experimental Section}

Phenylacetic acid $(98.5 \%)$ was recrystallized several times from cyclohexane, $\mathrm{mp} 76.5 \pm 0.5^{\circ} \mathrm{C}$ [lit. (9) $\mathrm{mp} 77^{\circ} \mathrm{C}$ ]. The recrystallized acid was titrated to a thymol blue end point with freshly standardized sodium methoxide by the method of Fritz and Lisickl (10), except toluene was substituted for benzene. The purity of the phenylacetic acid was calculated to be 99.7 $\pm 0.5 \%$. Cyclohexane $(99+\%)$, $n$-heptane $(99+\%), n$-octane $(99+\%)$, and isooctane $(99+\%)$ were stored over molecular sieves (type 4A) and distilled shortly before use. Carbon tetrachloride $(99 \%)$ was purifled by the method of Scatchard et al. (11), stored in contact with mercury under an argon atmosphere, and distilled shortly before use.

Solvent mixtures were prepared by weight with sufficient accuracy to allow calculation of compositions to 0.0001 mole fraction. Solvents and excess carboxylic acid were placed in amber glass containers and allowed to equilibrate in a constant-temperature shaker bath at $25.0 \pm 0.1^{\circ} \mathrm{C}$ for several days. Attainment of equilibrium was verified by repetitive measurements after several additional days. Acid solubilities were determined by transferring weight aliquots through a coarse filter into flasks containing blank nonaqueous titration solvent. The solutions were titrated with freshly standardized 
Table I. Comparison between Experimental and Predicted Solubilities for Phenylacetic Acid in Binary Solvent Mixtures at $25.0^{\circ} \mathrm{C}$

\begin{tabular}{|c|c|c|c|c|c|c|}
\hline \multirow[b]{2}{*}{$X_{1}^{\circ}$} & \multirow[b]{2}{*}{$X_{3}^{\text {sat }}$} & \multicolumn{4}{|c|}{ devn of calcd values, ${ }^{a} \%$} & \multirow{2}{*}{$\begin{array}{c}\Delta \bar{G}_{12}^{\text {ex }} \\
\operatorname{ref}\end{array}$} \\
\hline & & eq 1 & eq 2 & eq 3 & eq 4 & \\
\hline \multicolumn{7}{|c|}{$\mathrm{C}_{6} \mathrm{H}_{12}(1)+\mathrm{C}_{7} \mathrm{H}_{16}$} \\
\hline 0.0000 & 0.0134 & & & & & 12 \\
\hline 0.2523 & 0.0154 & -0.2 & -0.1 & +1.9 & +2.1 & \\
\hline 0.4491 & 0.0176 & -1.8 & -1.8 & +1.1 & +2.1 & \\
\hline 0.5756 & 0.0186 & +0.1 & +0.1 & +3.0 & +4.1 & \\
\hline 0.6932 & 0.0200 & +0.3 & +0.3 & +3.0 & +4.0 & \\
\hline 0.8409 & 0.0225 & -1.5 & -1.5 & +0.2 & +0.9 & \\
\hline 1.0000 & 0.0247 & & & & & \\
\hline \multicolumn{7}{|c|}{$\mathrm{CCl}_{4}(1)+\mathrm{C}_{7} \mathrm{H}_{16}(2)$} \\
\hline 0.0000 & 0.0134 & & & & & 13 \\
\hline 0.3350 & 0.0299 & -16.5 & -16.5 & -8.4 & -8.1 & \\
\hline 0.5029 & 0.0461 & -20.7 & -20.6 & -9.4 & -9.2 & \\
\hline 0.6192 & 0.0643 & -23.2 & -23.1 & -10.6 & -10.7 & \\
\hline 0.6996 & 0.0796 & -21.8 & -21.7 & -8.5 & -8.9 & \\
\hline 0.8556 & 0.123 & -16.2 & -16.1 & -5.6 & -6.2 & \\
\hline 1.0000 & 0.174 & & & & & \\
\hline \multicolumn{7}{|c|}{$\mathrm{CCl}_{4}(1)+\mathrm{C}_{6} \mathrm{H}_{12}$} \\
\hline 0.0000 & 0.0247 & & & & & 14 \\
\hline 0.3031 & 0.0499 & -14.1 & -14.0 & -7.1 & -8.0 & \\
\hline 0.4153 & 0.0655 & -18.9 & -18.9 & -10.1 & -11.1 & \\
\hline 0.5306 & 0.0820 & -18.7 & -18.8 & -9.3 & -10.6 & \\
\hline 0.6364 & 0.101 & -18.6 & -18.6 & -9.5 & -10.8 & \\
\hline 0.7169 & 0.116 & -16.2 & -16.2 & -7.6 & -8.7 & \\
\hline 0.8086 & 0.134 & -11.9 & -11.9 & -4.8 & -5.8 & \\
\hline 1.0000 & 0.174 & & & & & \\
\hline \multicolumn{7}{|c|}{$\mathrm{CCl}_{4}(1)+n-\mathrm{C}_{8} \mathrm{H}_{18}(2)$} \\
\hline 0.0000 & 0.0144 & & & & & 15 \\
\hline 0.3698 & 0.0309 & -13.6 & -13.9 & -5.5 & -4.5 & \\
\hline 0.5051 & 0.0439 & -18.9 & -19.1 & -9.0 & -8.1 & \\
\hline 0.6327 & 0.0615 & -20.4 & -20.6 & -8.8 & -8.1 & \\
\hline 0.7154 & 0.0781 & -20.6 & -20.7 & -8.3 & -7.9 & \\
\hline 0.8704 & 0.124 & -15.2 & -15.2 & -5.0 & -4.9 & \\
\hline 1.0000 & 0.174 & & & & & \\
\hline \multicolumn{7}{|c|}{$\mathrm{CCl}_{4}(1)+i-\mathrm{C}_{8} \mathrm{H}_{18}(2)$} \\
\hline 0.0000 & 0.0123 & & & & & 16 \\
\hline 0.2960 & 0.0245 & -16.3 & -16.5 & -9.1 & -8.0 & \\
\hline 0.4155 & 0.0334 & -21.0 & -21.0 & -11.2 & -9.9 & \\
\hline 0.5236 & 0.0445 & -23.8 & -24.0 & -12.1 & -11.5 & \\
\hline 0.6276 & 0.0616 & -27.1 & -27.3 & -14.1 & -13.4 & \\
\hline 0.6362 & 0.0621 & -26.0 & -26.2 & -12.9 & -12.1 & \\
\hline 0.7355 & 0.0824 & -24.2 & -24.5 & -10.0 & -10.3 & \\
\hline 0.8767 & 0.126 & -17.9 & -18.4 & -7.1 & -6.2 & \\
\hline 1.0000 & 0.174 & & & & & \\
\hline \multicolumn{7}{|c|}{$\mathrm{C}_{6} \mathrm{H}_{12}(1)+i-\mathrm{C}_{8} \mathrm{H}_{18}$} \\
\hline 0.0000 & 0.0123 & & & & & 17 \\
\hline 0.2767 & 0.0150 & -5.2 & -5.4 & -4.0 & -2.9 & \\
\hline 0.4521 & 0.0167 & -5.3 & -5.3 & -3.2 & -1.8 & \\
\hline 0.5548 & 0.0178 & -5.2 & -4.7 & -2.5 & -0.9 & \\
\hline 0.6535 & 0.0190 & -4.2 & -4.0 & -1.9 & -0.1 & \\
\hline 0.7333 & 0.0203 & -4.4 & -4.4 & -2.5 & -0.7 & \\
\hline 0.8602 & 0.0221 & -2.0 & -2.1 & -0.7 & +0.5 & \\
\hline 1.0000 & 0.0247 & & & & & \\
\hline
\end{tabular}

sodium methoxide solution to the thymol blue end point, glving solubilities reproducible to within $1.0 \%$. Solubilities in the pure and binary solvents are reported in Table I as formal mole fractions, calculated as though the solute were monomeric, and solvent compositions $\left(X_{1}{ }^{\circ}\right)$ are calculated as if the solute were not present.

\section{Discussion}

Comparisons between experimental and predlcted values are shown in the last four columns of Table I for the six binary solvent systems studied. Properties used in the calculations
Table II. Solvent Properties Used in the Calculations

\begin{tabular}{lc}
\hline \multicolumn{1}{c}{ compd } & $\bar{\nabla}_{i}^{\circ}, \mathrm{cm}^{3} / \mathrm{mol}$ \\
\hline carbon tetrachloride & 97.08 \\
cyclohexane & 108.76 \\
$n$-hexane & 131.51 \\
$n$-heptane & 147.48 \\
isooctane & 166.09 \\
$n$-octane & 163.46
\end{tabular}

Include the activity of the solld monomeric solute, $a_{3, \text { mon }}^{\text {sold }}=$ 0.4197 , calculated from

$$
\begin{gathered}
\text { In } a_{3, \text { mon }}^{\text {solld }}=\int_{T_{m p}}^{T}\left(\Delta \bar{H}_{3}^{\text {us }} / R T^{2}\right) d T \\
a_{3, \text { dim }}^{\text {solld }}=\left(a_{3, \text { mon }}^{\text {solld }}\right)^{2}
\end{gathered}
$$

the enthalpy of fusion data, $\Delta F_{3}^{\text {us }}=3464 \mathrm{cal} / \mathrm{mol}(9)$ at the normal melting point temperature $T_{\text {mp }}=77^{\circ} \mathrm{C}$. The enthalpy of fusion is actually for the transition of the solid to a mixture of monomers and dimers; but for consistency in these calculations, the melt is considered to be completely monomeric for the monomer model and completely dimeric for the dimer model. The molar volume of phenylacetic acid, $\bar{V}_{3, \mathrm{mon}}=121.8$ $\mathrm{cm}^{3} / \mathrm{mol}$, was obtained by adding an incremental " $\mathrm{CH}_{2}$ " volume of $17.4 \mathrm{~cm}^{3} / \mathrm{mol}$ to the molar volume of benzoic acid $\left(\bar{V}_{3, \text { mon }}\right.$ $=104.4 \mathrm{~cm}^{3} / \mathrm{mol}$ ). For systems studied in this investigation, a $10 \%$ error in estimating $\bar{V}_{3 \text {,mon }}$ affects the predicted solubilities by less than $1 \%$. Solvent properties used in the calculations are listed in Table II.

Inspection of Table I reveals that eq 3 and 4 are comparable with overall average (rms) deviations of $6.7 \%$ and $6.6 \%$, respectively, and are superior to equations based on the monomeric model. This is in agreement with observations from an earlier study involving benzoic and $m$-toluic acids. Although the magnitudes of the deviations between predicted and experimental phenylacetic acid solubilities appear large in comparison to the $2-4 \%$ deviations noted for benzoic acld solubillties, it must be noted that the phenylacetic acid solubilities cover up to a 15 -fold range whereas the benzolc acid solubilities cover a much smaller 5-fold range. Furthermore, phenylacetic acid is more soluble than benzoic acid in these solvent systems, and there is a greater possibility for specific interactions between the carboxylate group and the $\pi$-electron cloud on an adjacent solute molecule, which would violate the basic assumptions used in deriving eq 1-4. Despite these shortcomings, eq 3 and 4 do provide very reasonable predictions for the solubility of phenylacetic acid in the six binary solvent systems considered.

\section{Glossary}

$a_{3}^{\text {solld }}$ activity of the solid solute, defined as the ratio of the fugacity of the solid to the fugacity of the pure supercooled liquid

$\left(\Delta \bar{G}_{3}^{\text {ex }}\right)^{*}$ partial molar Glbbs free energy of the solute (Raoult's law), extrapolated back to infinite dilution $\left(\Delta \bar{G}_{3}^{m}\right)^{*} \quad$ partial molar Gibbs free energy of the solute (FloryHuggins model), extrapolated back to infinite dilution

$\Delta \bar{G}_{12}^{e x} \quad$ excess Gibbs free energy of the binary solvent mixture based on Raoult's law

$\Delta \bar{G}_{12}^{\text {th }}$ excess Gibbs free energy of the binary solvent mixture based on the Flory-Huggins solution model

$\Delta \bar{H}_{3}^{\text {ius }}$
$\bar{V}_{1}{ }^{\circ}{ }^{\circ}{ }^{\prime}{ }^{\circ}$ enthalpy of fusion of the solute molar volume of component I mole fraction compositions of the solvent mixture, calculated as if the solute were not present 


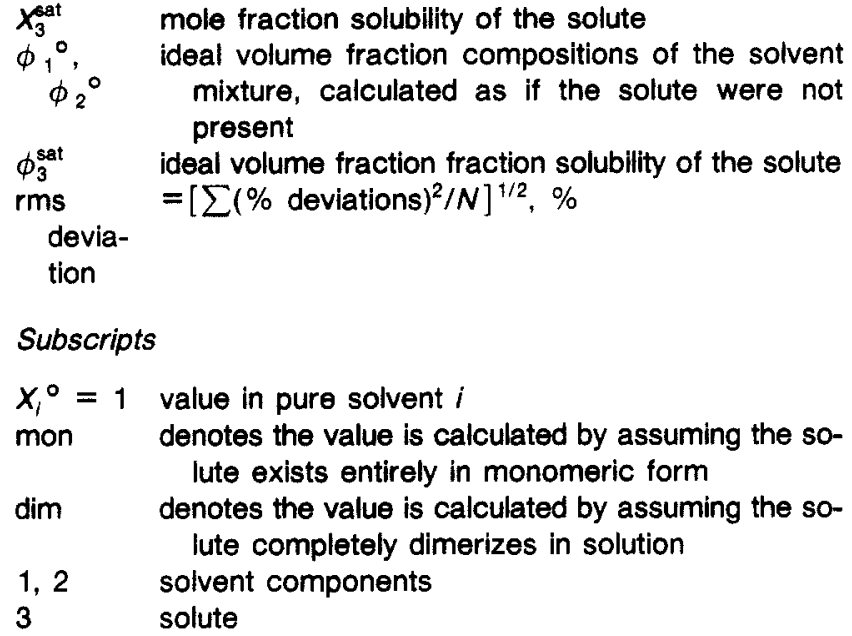

Reglatry No. $\mathrm{CCl}_{4}, 56-23-5 ; \mathrm{C}_{8} \mathrm{H}_{12}, 110-82-7 ; n-\mathrm{C}_{7} \mathrm{H}_{18}, 142-82-5 ; n-$ $\mathrm{C}_{8} \mathrm{H}_{18}, 111-65-9 ; i-\mathrm{C}_{8} \mathrm{H}_{18}, 540-84-1 ;$ phenylacetic acid, 103-82-2.

\section{Literature Clted}

(1) Acree, W. E., Jr.; Bertrand, G. L. J. Phys . Chem. 1977, 81, 1170-3.

(2) Acree, W. E., Jr.; Bertrand, G. L. J. Phys , Chem, 1979, 83, 2355-8.

(3) Acree, W. E., Jr.; Bertrand, G. L. J. Pharm. Sci, 1981, 70, 1033-6.

(4) Acree, W. E., Jr.; Rytting, J. H. J. Pharm. Sci. 1982, 7i, 201-5.

(5) Acree, W. E., Jr.; Rytting, J. H. Int. J. Pharm. 1982, 10, 231-8.

(6) Acree, W. E., Jr. J. Phys. Chem. 1982, 86, 1461-5.

(7) Acree, W. E., Jr.; Rytting, J. H. J. Pharm. Sci. 1983, 72, 292-6.

(8) Acree, W. E., Jr.; Bertrand, G. L. J. Solution Chem. 1983, 12, 101-13.

(9) Weast, R. C., Ed. "Handbook of Chemistry and Physics", 64th ed.; CRC Press: Boca Raton, FL, 1983.

(10) Fritz, J. S.; Lisickl, N. M. Anal. Chem. 1951, 23, 589-91.

(11) Scatchard, G.; Wood, S. E.; Mochel, J. M. J. Am. Chem. Soc. 1939. 61, 3206-10.

(12) Young, K. L.; Mentzer, R. A.; Greenkorn, R. A.; Chao, K. C. J. Chem Thermodyn. 1977, 9, 979-85.

(13) Bissell, T, G. Williamson, A, G. $J$, Chem. Thermodyn, 1975, 7 , 131-6.

(14) Goates, J. R.; Sullivan, R. J.; Ott, J. B. J. Phys. Chem. 1959, 63, $589-94$.

(15) Jain, D. V. S.; Gupta, V. K.; Lark, B. S. Indian J. Chem. 1971, 9 465-8

(16) Battino, R. J. Phys, Chem. 1968, 72, 4503-8

(17) Battino, R. J. Phys. Chem. 1966, 70, 3408-16.

Received for review February 16, 1984. Accepted July 9, 1984.

\title{
Isobaric Vapor-Liquid Equilibria of the Binary Systems Consisting of Anisaldehyde, Methyl Anisate, and Anisyl Alcohol at $2 \mathrm{kPa}$
}

\author{
Andreas G. R. Scholz * and Erwin Brunner \\ BASF Aktiengesellschaft, D-6700 Ludwigshafen/Rhein, Federal Republic of Germany
}

The vapor pressures of the three pure components anlsaldehyde, methyl anisate, and anisyl alcohol have been determined experimentally, together with the three blnary vapor-llquid equillbria. The vapor pressures have been measured ebulliometrically, and the vapor-llquld equilibria by using a recirculation-type equilibrium still. The methyl anisate/anisyl alcohol system forms an azeotrope. Data reduction based on the Wilson, NRTL, and UNIQUAC models provides a correlation for the actlvity coefficients $\gamma_{1}$.

\section{Introduction}

In connection with the problem of separating anisaldehyde (4-methoxybenzaldehyde), methyl anisate (methyl 4-methoxybenzoate), and anisyi alcohol (4-methoxybenzyl alcohol) by distillation, the vapor pressures of the pure components, and the three corresponding binary vapor-liquid phase equilibria, have been measured. Because anisyl alcohol is thermally unstable, the separation by distillation has to be carried out under reduced pressure. Hence, the binary vapor-liquid phase equilibria have been measured at $2 \mathrm{kPa}$.

\section{Experimental Section}

Purtly of Components. The reagents were manufactured by BASF Aktiengesellschaft, Federal Republic of Germany. Their purity was confirmed by gas chromatography. The aldehyde and alcohol had a mole fraction purity better than $99.5 \%$, while the mole fraction purity of the ester was $99.9 \%$.

Apparatus and Procedure. The vapor pressures of the pure components have been determined ebulliometrically with an apparatus similar to apparatus I, described by Ambrose and
Table I. Experimental Vapor Pressure of Anisaldehyde

\begin{tabular}{rccccc}
\hline$t /{ }^{\circ} \mathrm{C}$ & $p^{\circ} / \mathrm{kPa}$ & $t /{ }^{\circ} \mathrm{C}$ & $p^{\circ} / \mathrm{kPa}$ & $t /{ }^{\circ} \mathrm{C}$ & $p^{\circ} / \mathrm{kPa}$ \\
\hline 74.7 & 0.15 & 110.9 & 1.00 & 189.0 & 20.0 \\
83.6 & 0.25 & 126.3 & 2.00 & 212.6 & 40.0 \\
92.5 & 0.40 & 146.0 & 4.50 & 233.8 & 70.0 \\
100.4 & 0.60 & 167.9 & 10.0 & 248.7 & 100.0
\end{tabular}

Table II. Experimental Vapor Pressure of Methyl Anisate

\begin{tabular}{cccccc}
\hline$t /{ }^{\circ} \mathrm{C}$ & $p^{\circ} / \mathrm{kPa}$ & $t /{ }^{\circ} \mathrm{C}$ & $p^{\circ} / \mathrm{kPa}$ & $t /{ }^{\circ} \mathrm{C}$ & $p^{\circ} / \mathrm{kPa}$ \\
\hline 108.6 & 0.54 & 151.4 & 3.70 & 181.5 & 11.20 \\
121.3 & 1.00 & 160.2 & 5.20 & 191.8 & 15.70 \\
132.7 & 1.71 & 168.2 & 7.00 & 198.7 & 19.50 \\
137.9 & 2.15 & & & &
\end{tabular}

Table III. Experimental Vapor Pressure of Anisyl Alcohol

\begin{tabular}{cccccc}
\hline$t /{ }^{\circ} \mathrm{C}$ & $p^{\circ} / \mathrm{kPa}$ & $t /{ }^{\circ} \mathrm{C}$ & $p^{\circ} / \mathrm{kPa}$ & $t /{ }^{\circ} \mathrm{C}$ & $p^{\circ} / \mathrm{kPa}$ \\
\hline 80.6 & 0.060 & 114.3 & 0.50 & 162.2 & 5.00 \\
87.9 & 0.10 & 127.3 & 1.00 & 179.8 & 9.99 \\
98.6 & 0.20 & 141.4 & 2.00 & &
\end{tabular}

Sprake (1). The apparatus used to obtain vapor-liquid equilibrium data was a modified Hunsmann vapor-liquid recirculation still (2) with several modifications suggested by Brunner and Scholz $(3,4)$.

Pressures were measured by means of a high-accuracy electronic manometer from MKS Instruments Inc., Burlington, $M A$, with an accuracy of $\Delta p / p=5 \times 10^{-4}$. The pressure transducer was calibrated against a dead-weight gage. The pressure constancy $\Delta p / p$ was better than $5 \times 10^{-4}$. The temperatures (IPTS-68) were measured by using a calibrated temperature meter (from Systemteknik, Sweden, 1220 series) which had a digital resolution of $0.01 \mathrm{~K}$ and whose accuracy was estimated to be $0.02 \mathrm{~K}$. The temperatures measured were reproducible within $0.05 \mathrm{~K}$. 